\title{
Reaction of Ptr ToxA-Insensitive Wheat Mutants to Pyrenophora tritici-repentis Race 1
}

\author{
T. L. Friesen, J. B. Rasmussen, C. Y. Kwon, S. Ali, L. J. Francl, and S. W. Meinhardt
}

First, second, third, fourth, and fifth authors: Department of Plant Pathology North Dakota State University, Fargo 58105; and sixth author: Department of Biochemistry, North Dakota State University, Fargo 58105.

Accepted for publication 17 September 2001.

\begin{abstract}
Friesen, T. L., Rasmussen, J. B., Kwon, C. Y., Ali, S., Francl, L. J., and Meinhardt, S. W. 2002. Reaction of Ptr ToxA-insensitive wheat mutants to Pyrenophora tritici-repentis race 1. Phytopathology 92:38-42.

The host-selective toxin Ptr ToxA is produced by races 1 and 2 of Pyrenophora tritici-repentis, causal agent of tan spot of wheat. Ptr ToxA has been causally associated with pathogenicity by the race 2 phenotype in this system. However, the role of toxin in disease caused by race 1, the most prevalent form of the fungus in the central and northern Great Plains of North America, has not been rigorously investigated. Three independent wheat lines harboring mutations for insensitivity to Ptr ToxA were derived from ethylmethane sulfonate treatment of the hard red spring wheat $\mathrm{cv}$. Kulm, possessing the single dominant gene for toxin sensitivity. Each of the three mutants was insensitive to Ptr ToxA in bio-
\end{abstract}

ABSTRACT

Tan spot, caused by the fungus Pyrenophora tritici-repentis (Died.) Drechs., is a major foliar disease of wheat (Triticum aestivum L.) in many regions of the world. Localized or widespread epidemics of the disease develop annually throughout much of the wheat-producing regions of North America, including the Great Plains. Most commercially accepted cultivars of wheat are susceptible to the disease.

Five races of $P$. tritici-repentis have been described (14). Race 1 of the fungus, the most prevalent race in commercial fields of the Great Plains $(1,13)$, typically produces necrotic lesions (nec+) surrounded by chlorotic halos (chl+) on susceptible wheat. By comparison, race 2 produces necrosis only (nec+, chl-) and is more rare in commercial wheat fields. Races 3 and 5 both produce chlorosis only (nec-, chl+) and are differentiated by host varieties affected (14). Race 4 (nec-, chl-) is avirulent on wheat, but can be isolated from wild grass species in North America (1).

Races 1 and 2 produce Ptr ToxA, a 13.2-kDa protein that causes necrosis development in certain genotypes of wheat (2). Insensitivity to toxin is controlled by a single recessive wheat gene, designated $t s n 1$, located on chromosome 5BL $(5,18)$. A perfect correlation was observed between sensitivity to Ptr ToxA and susceptibility to race 2 of the fungus in segregating host populations (12), suggesting that Ptr ToxA is a host-selective toxin (HST) with a significant or causal role in disease development $(11,12)$. ToxA, the gene that directly encodes Ptr ToxA, was cloned and introduced into an avirulent, toxin-deficient race 4 isolate of the fungus (3). Transformants were toxin-producing and pathogenic on wheat, mimicking the race 2 (nec+, chl-) phenotype. Based on these ob-

Corresponding author: J. Rasmussen

E-mail address: jack.rasmussen@ndsu.nodak.edu

Publication no. P-2001-1119-01R

(C) 2002 The American Phytopathological Society assays based on necrosis development and electrolyte leakage. Each mutant was crossed to each of the other mutants and to the wild-type Kulm. Segregation data indicate that each mutant line harbors a single recessive mutation for toxin insensitivity that maps to or near the same locus, possibly the toxin-sensitivity gene. Each toxin-insensitive mutant line was susceptible to two isolates of race 1 of $P$. tritici-repentis. $\mathrm{F}_{2}$ and $\mathrm{F}_{3}$ generations derived from crosses between Kulm and each mutant segregated for toxin reaction. However, segregation for fungal reaction was not evident, and all $\mathrm{F}_{3}$ families were tan spot susceptible regardless of toxin reaction. Host insensitivity to $\operatorname{Ptr} \operatorname{ToxA}$ is not necessarily equivalent to resistance to race 1 . Ptr ToxA should not be used alone as a proxy for fungal inoculations by breeding programs aimed at developing tan spot-resistant wheat.

Additional keywords: phytotoxin, Triticum aestivum. servations, Ptr ToxA has been described as the primary determinant of pathogenicity for tan spot disease (3). This is consistent with HSTs such as victorin and HC toxin, produced by Cochliobolus victoriae and $C$. carbonum race 1 , respectively, which also are required for disease $(15,17)$.

Although a clear genetic association has been made between Ptr ToxA and tan spot disease, most of the available work has used isolates of the fungus with the race 2 phenotype (nec+, chl-). The precise role of Ptr ToxA in disease caused by race 1 of $P$. triticirepentis, the only other race known to produce the toxin, has not been rigorously investigated. Lamari and Bernier (11), working with segregating host populations, reported that a single recessive gene for insensitivity to $\mathrm{Ptr}$ ToxA, presumably $t s n 1$, correlated with resistance to ASC1, a race 1 isolate of the fungus. This is consistent with Ptr ToxA acting as a pathogenicity factor for race 1 , but this conclusion has not been supported by other direct experimental evidence. Elucidating the precise role of Ptr ToxA in a race 1 reaction is significant for at least two reasons. First, a detailed understanding of this important pathosystem requires that the role in disease of Ptr ToxA, if any, be determined for all races of the fungus that produce the toxin. Second, as outlined previously, race 1 is the predominant form of the fungus in wheat fields of the northern Great Plains and possibly beyond (1,13). Accordingly, race 1 is the form of the fungus that must be dealt with by producers and breeding programs. A clear understanding of the role of Ptr ToxA in disease caused by race 1 may influence strategies aimed at developing tan spot resistant wheat. For example, it has been postulated that Ptr ToxA might be used as a selection tool for developing tan spot resistant lines $(4,11)$. For this to be a valid practice, however, there should be an absolute correlation between insensitivity to toxin and resistance to race 1 of the fungus. This association has not been experimentally demonstrated.

The objective of this study was to determine whether insensitivity to Ptr ToxA is equated to resistance to race 1 of $P$. tritici- 
repentis. The approach used was based on the isolation and characterization of wheat lines harboring mutations for insensitivity to Ptr ToxA. The hard red spring wheat cv. Kulm, known to possess a single dominant gene for toxin sensitivity (5) and to be susceptible to $P$. tritici-repentis, was chosen for mutagenesis.

\section{MATERIALS AND METHODS}

Biological materials. Hard red spring wheat cvs. Kulm (toxin sensitive and tan spot susceptible) and Erik (toxin insensitive and tan spot resistant) were obtained from R. Frohberg, North Dakota State University. To ensure genetic uniformity, seeds of each were increased in the greenhouse away from other wheat lines by the single seed descent method. Disease evaluations made use of two race 1 isolates of $P$. tritici-repentis. One isolate (Pti2) was obtained from a South Dakota wheat field and the other (ASC1) was obtained from L. Lamari, University of Manitoba. Culture filtrates of both isolates and pure Ptr ToxA were produced as described previously (20).

Mutant isolation. The mutagenesis protocol was modified from Haughn and Somerville (6). Seeds of Kulm were soaked in $10 \mathrm{mM}$ ethyl methanesulfonate (EMS) (Sigma Chemical, St. Louis) for $18 \mathrm{~h}$ in a chemical fume hood. Following treatment, seeds were rinsed for $6 \mathrm{~h}$ in running tap water and were planted in clay pots in the greenhouse. To increase the probability of obtaining independent mutants, $M_{2}$ seeds were harvested from individual $M_{1}$ plants and hand threshed. Five hundred fifteen $\mathrm{M}_{2}$ families (16 seedlings per family) were evaluated for reaction to Ptr ToxA at 14 to 20 days after planting by infiltrating pure Ptr ToxA $\left(3 \mu \mathrm{g} \mathrm{ml}^{-1}\right)$ into the second leaf. Three days later, seedlings were evaluated for presence or absence of necrosis in the infiltrated region.

Toxin bioassays, host genetic analyses, and fungal inoculations. Toxin bioassays were based on necrosis development in intact seedlings $72 \mathrm{~h}$ after infiltration and on electrolyte leakage in leaf sections $(7,8)$. All bioassay experiments made use of toxin at $10 \mu \mathrm{g} \mathrm{ml}^{-1}$ unless otherwise noted.

Each mutant was crossed to wild-type Kulm and to each of the other mutants. $F_{2}$ individuals and $F_{3}$ families were produced in the greenhouse. Segregation for toxin sensitivity and insensitivity was determined for both the $F_{2}$ populations and $F_{3}$ families derived from mutant $\times$ Kulm crosses. $F_{3}$ families were characterized genetically as homozygous toxin sensitive, heterozygous, or homozygous toxin insensitive based on the reaction to Ptr ToxA of 16 individuals.

Inoculation of plants with $P$. tritici-repentis isolates Pti2 and ASC1 (3,000 conidia per $\mathrm{ml}$ ) was completed as described previously (16). Following inoculations, plants were incubated in growth chambers on a 16-h photoperiod and day and night temperatures of 22 and $18^{\circ} \mathrm{C}$, respectively. Plants were scored for reaction to the fungus 1 week after inoculation on a scale of 1 (resistant) to 5 (susceptible) (9). A total of 115 homozygous toxinsensitive and 122 toxin-insensitive families derived from the mutant $\times$ Kulm crosses were evaluated for reaction to Pti2. Progeny of the three crosses were evaluated in different inoculation experiments. In each inoculation event, 16 individuals from Kulm, Erik, the parental mutant of the cross in question, and of each $F_{3}$ family derived from the cross were inoculated at once. In other experiments, $F_{2}$ individuals and homozygous $F_{3}$ families were inoculated with strain ASC1, the second race 1 isolate.

Intercellular wash fluids. Intercellular wash fluids (IWFs) were collected from healthy (not inoculated) Kulm, diseased Kulm, and diseased mutant leaves 7 days after inoculation as described (9). Undiluted IWFs were infiltrated into Kulm and each mutant. Infiltrated plants were scored for presence or absence of necrosis 3 days later.

Statistical analyses. Significant differences $(P=0.05)$, where reported, were determined by analysis of variance and least significant difference mean separation. Electrolyte leakage data are mean and standard deviation of two replicates for each treatment. Disease reaction data are the mean and standard deviation of 16 individuals from each wheat line or $\mathrm{F}_{3}$ family. All data reported are results of a single experiment that was repeated at least one time with similar results.

\section{RESULTS}

Mutant isolation and response to Ptr ToxA. Three independent toxin-insensitive $\mathbf{M}_{2}$ seedlings, designated hereafter as M37, M103, and M322, were isolated by the necrosis bioassay in the screen of $515 \mathrm{M}_{2}$ families. The wild-type Kulm developed necrosis within $72 \mathrm{~h}$ of infiltration with Ptr ToxA $\left(10 \mu \mathrm{g} \mathrm{ml}^{-1}\right)$, but each mutant and the toxin-insensitive Erik did not (Fig. 1). In another experiment, necrosis developed in Kulm but failed to develop in
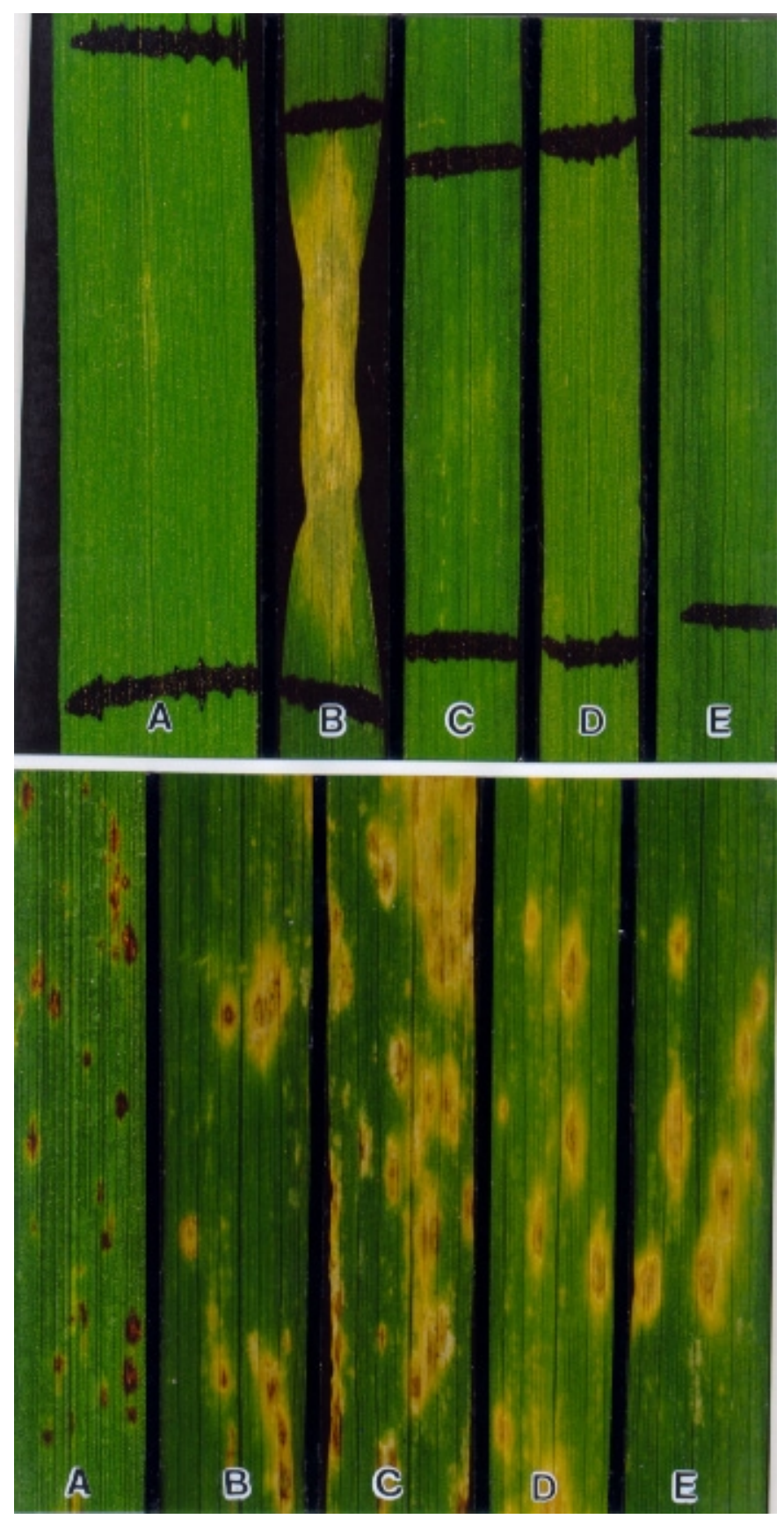

Fig. 1. Reaction of wheat cultivars and mutants to $10 \mu \mathrm{g} \mathrm{ml}^{-1} \mathrm{Ptr}$ ToxA (top) and to inoculation with Pyrenophora tritici-repentis isolate Pti2 (bottom). Wheat lines are A, Erik and B, Kulm, and the toxin-insensitive mutants are C, M37, D, M103, and E, M322. 
the three mutants and in Erik in response to Ptr ToxA at $75 \mu \mathrm{g} \mathrm{ml}^{-1}$, the highest concentration tested. Toxin insensitivity of M37, M103, and M322 was confirmed in electrolyte leakage assays (Table 1). Kulm gave significantly higher electrolyte leakage in response to toxin than did each mutant. In addition, conductivity

TABLE 1. Effect of Ptr ToxA $\left(10 \mu \mathrm{g} \mathrm{m}^{-1}\right)$ on electrolyte leakage from cv. Kulm and each mutant

\begin{tabular}{llr}
\hline Experiment & Treatment & Conductivity values $(\mu S)^{\mathrm{z}}$ \\
\hline 1 & Kulm + toxin & $27.4 \pm 1.5 \mathrm{a}$ \\
& Kulm + water & $4.7 \pm 0.4 \mathrm{~b}$ \\
& M37 + toxin & $4.1 \pm 0.2 \mathrm{~b}$ \\
& M37 + water & $4.3 \pm 0.1 \mathrm{~b}$ \\
2 & Kulm + toxin & $26.3 \pm 1.7 \mathrm{a}$ \\
& Kulm + water & $4.9 \pm 0.1 \mathrm{~b}$ \\
& M103 + toxin & $4.2 \pm 0.4 \mathrm{~b}$ \\
& M103 + water & $4.0 \pm 0.4 \mathrm{~b}$ \\
& Kulm + toxin & $37.6 \pm 5.1 \mathrm{a}$ \\
& Kulm + water & $5.2 \pm 0.2 \mathrm{~b}$ \\
& M322 + toxin & $4.8 \pm 0.4 \mathrm{~b}$ \\
& M322 + water & $4.4 \pm 0.1 \mathrm{~b}$ \\
\hline
\end{tabular}

${ }_{\mathrm{z}}$ Each experiment was conducted on a different day. Experiments were conducted according to Kwon et al. (7). Data are mean \pm SD for two replicates of five leaves per treatment. Means followed by a different letter within an experiment are significantly different from each other $(P=0.05)$ determined by analysis of variance and least significant difference mean separation.

TABLE 2. Effect of Ptr ToxA $\left(10 \mu \mathrm{g} \mathrm{ml}^{-1}\right)$ on electrolyte leakage from $\mathrm{F}_{1}$ progeny of crosses between M103 $\times$ Kulm and M322 $\times$ Kulm

\begin{tabular}{lcr}
\hline & \multicolumn{2}{c}{ Conductivity $^{\mathrm{z}}$} \\
\cline { 2 - 3 } Genotype & Water-treated & \multicolumn{1}{c}{ Toxin-treated } \\
\hline M103 & $5.1 \pm 0.2 \mathrm{a}$ & $5.0 \pm 1.4 \mathrm{a}$ \\
$\mathrm{F}_{1}$ progeny & $7.2 \pm 0.2 \mathrm{a}$ & $22.0 \pm 0.6 \mathrm{~b}$ \\
Kulm & $7.1 \pm 0.5 \mathrm{a}$ & $48.0 \pm 3.4 \mathrm{c}$ \\
M322 & $5.0 \pm 0.2 \mathrm{a}$ & $4.5 \pm 1.0 \mathrm{a}$ \\
F $_{1}$ progeny & $6.0 \pm 0.6 \mathrm{a}$ & $24.8 \pm 2.8 \mathrm{~b}$ \\
Kulm & $5.4 \pm 0.2 \mathrm{a}$ & $37.5 \pm 2.1 \mathrm{c}$ \\
\hline
\end{tabular}

${ }^{\mathrm{z}}$ The two experiments were performed on different days. Experiments were conducted according to Kwon et al. (7). Data are mean \pm SD conductivity values of two replicates per treatment. Means followed by different letters are significantly different $(P=0.05)$ determined by analysis of variance and least significant difference mean separation.

TABLE 3. Segregation for toxin sensitivity/insensitivity in $F_{2}$ populations derived from crosses of each mutant by Kulm ${ }^{\mathrm{z}}$

\begin{tabular}{lcccc}
\hline & \multicolumn{2}{c}{$\mathrm{F}_{2}$ progeny } & & \\
\cline { 2 - 3 } Cross & $\begin{array}{c}\text { Toxin } \\
\text { sensitive }\end{array}$ & $\begin{array}{c}\text { Toxin } \\
\text { insensitive }\end{array}$ & $\chi^{2}$ & $P$ \\
\hline M37 $\times$ Kulm & 90 & 32 & 0.099 & $0.75-0.90$ \\
M103 $\times$ Kulm & 118 & 47 & 1.069 & $0.25-0.50$ \\
M322 $\times$ Kulm & 127 & 43 & 0.008 & $0.90-0.99$ \\
\hline
\end{tabular}

${ }_{\mathrm{z}}$ Bioassay was based on necrosis development $72 \mathrm{~h}$ after infiltration with Ptr ToxA $\left(10 \mu \mathrm{g} \mathrm{ml} \mathrm{m}^{-1}\right) \cdot \chi^{2}$ values are based on an expected 3:1 ratio of toxin sensitive/insensitive individuals. values from toxin-treated mutants were not significantly different from those of water-treated mutants (Table 1). Toxin insensitivity had been stable for each mutant line through four generations (data not shown).

Genetics of toxin reaction. $F_{1}$ seedlings derived from all mutant $\times$ Kulm crosses developed necrosis after infiltration with Ptr ToxA, suggesting that mutations to toxin insensitivity were recessive. The rate and extent of necrosis development was indistinguishable from that on Kulm. However, in the more quantitative electrolyte leakage assay, leaves from $F_{1}$ seedlings derived from crosses between M103 $\times$ Kulm and M322 × Kulm gave responses to toxin that were intermediate to those of the parents (Table 2). $F_{1}$ seedlings from crosses of M37 $\times$ Kulm were not tested this way.

$\mathrm{F}_{2}$ populations from mutant $\times$ Kulm crosses segregated 3:1 (toxin sensitive/toxin insensitive), which is consistent with a single recessive mutation to toxin insensitivity in each line (Table 3 ). This conclusion was supported by segregation data from $F_{3}$ families, all of which segregated 1:2:1 as homozygous toxin sensitive/heterozygous/homozygous toxin insensitive (Table 4). All $\mathrm{F}_{2}$ individuals from all combinations of mutant $\times$ mutant crosses were toxin insensitive (data not shown), suggesting that mutations affected the same gene or multiple closely linked genes. All $\mathrm{F}_{2}$ progeny from mutant $\times$ Erik crosses were toxin insensitive (data not shown).

Reaction to $P$. tritici-repentis race 1 . Kulm, each mutant, and all $\mathrm{F}_{3}$ families evaluated showed moderately susceptible to susceptible disease reactions (disease scores of 4 and 5, respectively) when inoculated with both race 1 isolates. When inoculated with Pti2, Kulm and the three mutant lines all developed necrotic lesions surrounded by chlorosis (Fig. 1), which is typical of tan spot disease caused by race 1 (10). In some inoculations (Fig. 1), lesions that formed on the mutants appeared to be less delimited and consisted of more chlorosis than those on Kulm. By comparison, the most common reaction of Erik consisted of dark brown or black spots at the point of attempted penetration. Some lesions on Erik developed small amounts of limited necrosis. These reactions, typical of resistance to tan spot, have been noted before for Erik (10). Similar disease reactions were observed for all wheat lines with the second race 1 isolate, ASC1 (data not shown).

Effect of culture filtrates and IWF on necrosis development. Experiments to this point demonstrated necrosis development and enhanced electrolyte leakage in Kulm but not in the three mutants in response to Ptr ToxA. However, lesions containing necrosis were evident in the three mutants after inoculation with race 1 of P. tritici-repentis. One possible explanation for these observations is that the mutants detected a necrosis-inducing factor or toxin produced by the fungus other than Ptr ToxA. To test this possibility, we infiltrated Kulm and each of the mutants with culture filtrates from two race 1 strains of the fungus and with IWF obtained from infected leaves. Necrosis developed in Kulm but not in the mutants after infiltration with the culture filtrates from P. tritici-repentis strains ASC1 and Pti2 (Table 5). Necrosis development in Kulm but not in any of the mutants was also observed when leaves were infiltrated with IWF obtained from infected leaves of Kulm and from the M37 mutant (Table 5).

TABLE 4. Segregation for toxin reaction in $\mathrm{F}_{3}$ families of mutant $\times$ Kulm crosses

\begin{tabular}{|c|c|c|c|c|c|}
\hline \multirow[b]{2}{*}{ Cross } & \multicolumn{3}{|c|}{$\mathrm{F}_{3}$ families $^{\mathrm{z}}$} & \multirow[b]{2}{*}{$\chi^{2}$} & \multirow[b]{2}{*}{$P$} \\
\hline & Homozygous sensitive & Heterozygous & Homozygous insensitive & & \\
\hline M37 × Kulm & 34 & 56 & 32 & 0.886 & $0.50-0.75$ \\
\hline M103 × Kulm & 34 & 84 & 47 & 2.100 & $0.25-0.50$ \\
\hline M322 × Kulm & 47 & 80 & 43 & 0.776 & $0.50-0.75$ \\
\hline
\end{tabular}

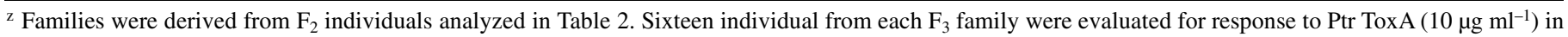
the assay based on necrosis development. A ratio of 1:2:1 (homozygous sensitive/segregating/homozygous insensitive) was expected. 


\section{DISCUSSION}

Three independent toxin-insensitive mutants were identified from a screen of $515 \mathrm{M}_{2}$ families derived from EMS-treated Kulm wheat. Kulm was previously known to be tan spot susceptible and to possess a single dominant gene for sensitivity to Ptr ToxA (5). Each mutant was insensitive to Ptr ToxA in bioassays based on necrosis development and on electrolyte leakage (Fig. 1; Table 1). Each of the mutants failed to develop necrosis in response to toxin at $75 \mu \mathrm{g} \mathrm{ml}{ }^{-1}$, the highest concentration tested. By comparison, many toxin-sensitive wheats, including Kulm, developed necrosis when infiltrated with toxin at $1 \mu \mathrm{g} \mathrm{ml}^{-1}$. Necrosis develops in less than $48 \mathrm{~h}$ when Kulm is infiltrated with toxin at $5 \mu \mathrm{g} \mathrm{ml}^{-1}$. As expected, the toxin-insensitive Erik failed to develop necrosis (Fig. 1) or to develop electrolyte leakage (data not shown) when infiltrated with toxin. Erik was previously demonstrated to not respond to toxin in other electrolyte leakage experiments (7).

Each mutant was crossed to Kulm. $\mathrm{F}_{1}$ progeny were intermediate for toxin reaction, relative to the parents in electrolyte leakage experiments (Table 2). This suggested that each mutant line harbors a recessive mutation and that toxin sensitivity is incompletely dominant. $\mathrm{F}_{2}$ progeny from these crosses segregated 3:1 (toxin sensitive/toxin insensitive), and $\mathrm{F}_{3}$ families segregated 1:2:1 (homozygous sensitive/heterozygous/homozygous insensitive) (Table 4). Progeny of inter-mutant crosses were all insensitive to toxin (data not shown). The genetic data collectively indicate that each mutant line possesses a single recessive mutation for toxin insensitivity that maps to or near the same locus. The gene for toxin sensitivity in Kulm has not been cloned but resides on chromosome 5BL (5). It is possible that each mutation affects the toxin sensitivity gene on $5 \mathrm{BL}$, although this cannot be proven with available tools. It must be kept in mind, however, that toxininduced necrosis development in wheat requires host signaling processes and de novo gene expression (8). Thus, it is possible that toxin insensitivity could result from mutations in host genes other than the gene on 5BL. If the mutations did occur at the same locus, the gene in question would appear to be highly mutable because the three mutants were isolated from only $515 \mathrm{M}_{2}$ families.

Although there was clear segregation in the $F_{2}$ and $F_{3}$ generations for reaction to purified toxin, there was no visible segregation for reaction to race 1 inoculations. Each mutant, Kulm, and all progeny derived from crosses between mutants and Kulm were susceptible to two commonly used race 1 isolates of $P$. triticirepentis, regardless of toxin reaction. Thus, the data indicate that host sensitivity to Ptr ToxA is not required for susceptibility to race 1 . By extension, Ptr ToxA may not be a pathogenicity factor required for disease caused by race 1 . In at least some of the inoculations, Kulm developed more defined lesions that appeared to possess more necrosis than did the mutants, although the disease severities were similar (Fig. 1). The evidence here is not conclusive, but Ptr ToxA may be partially responsible for the type or appearance of tan spot lesions caused by race 1 . If so, the toxin

TABLE 5. Effect of diluted culture filtrates of Pyrenophora tritici-repentis and undiluted intercellular wash fluids (IWF) on necrosis development in wild-type Kulm and the three mutants

\begin{tabular}{lcccc}
\hline & \multicolumn{4}{c}{ Necrosis development ${ }^{\mathrm{z}}$} \\
\cline { 2 - 5 } Material infiltrated & Kulm & M37 & M103 & M322 \\
\hline Culture filtrates from Pti2 and ASC1 & Yes & No & No & No \\
IWF from healthy Kulm & No & No & No & No \\
IWF from diseased Kulm & Yes & No & No & No \\
IWF from diseased M37 & Yes & No & No & No \\
Ptr ToxA at $75 \mu \mathrm{g} \mathrm{ml}^{-1}$ & Yes & No & No & No \\
\hline
\end{tabular}

${ }^{y}$ Filtrates from 21-day-old cultures were filter sterilized and diluted 1:20 with distilled water. IWF were not diluted prior to infiltration.

${ }^{\mathrm{z}}$ Presence or absence of necrosis was scored 3 days after infiltration. might be better viewed as a virulence factor, as described by Scheffer (17), for race 1. Additional studies, including sitedirected disruption of ToxA in race 1, are needed to clarify these possibilities.

It is interesting that the mutants developed necrosis in response to race 1 . The basis for this currently is not understood. Attempts were made to identify a toxin or factor other than Ptr ToxA that might induce necrosis in the mutants. In those experiments, leaves of Kulm and each mutant were infiltrated with crude culture filtrates of the two race 1 isolates and with IWF from infected plants. Kulm developed necrosis in response to these treatments, probably in response to $\operatorname{Ptr}$ ToxA in the culture filtrates and IWF. However, necrosis failed to develop in any of the mutants in response to race 1 culture filtrates or IWF (Table 5). Thus, no necrosis-inducing toxins or metabolites other than Ptr ToxA were detected. Tuori et al. (19) reported multiple forms of necrosis toxin in their culture filtrates of $P$. tritici-repentis. To our knowledge, the chemical nature of those analogs has not been reported. Because no necrosis was detected in the mutants in response to IWFs or culture filtrates, it appears that either multiple forms of toxin were not produced by the strains used or, if they were produced, they were not active against the mutants. Preliminary findings indicate that a chlorosis toxin is produced by at least some race 1 isolates ( $\mathrm{S}$. W. Meinhardt, unpublished data). This, along with other potential disease determinants not yet identified, may be important in the race 1 reactions observed in this study.

The use of induced mutations in the host is a powerful tool for studying the role of toxin in disease, but our results may be subject to unknown variables in the race 1 pathosystem. For example, although the mutants failed to respond to toxin at $75 \mu \mathrm{g} \mathrm{m} l^{-1}$ (Table 5), which is about 75-fold over the minimum concentration for toxin activity, the effective concentration of Ptr ToxA in the infection court of inoculated plants is not known. It is possible that toxin levels are higher there and that mutants are responding to those higher levels.

It was demonstrated that toxin-insensitive wheats are susceptible to two isolates of a common race of the fungus. Based on this observation alone, breeding programs aimed at developing tan spot resistant wheats probably should not rely on toxin reactions to guide the selection of wheat lines. It would appear from this study that breeders or pathologists could select for toxin-insensitive wheats that are tan spot susceptible.

To date, most work aimed at elucidating the role of toxin in tan spot disease has focused on the race 2 phenotype. In those reports, classical genetics with the host (12) and molecular genetics with the fungus (3) were used to demonstrate Ptr ToxA as a pathogenicity factor required for disease. The experiments reported here focus only on race 1 . Thus, the results do not contradict previous claims that toxin is a key determinant of disease caused by race 2 .

\section{LITERATURE CITED}

1. Ali, S., and Francl, L. J. 1998. Race structure of Pyrenophora triticirepentis isolated from wheat and grasses in the US Great Plains. (Abstr.) Phytopathology 88(suppl.):S114.

2. Ciuffetti, L. M., Francl, L. J., Ballance, G. M., Bockus, W. W., Lamari, L., Meinhardt, S. W., and Rasmussen, J. B. 1998. Standardization of the toxin nomenclature in the Pyrenophora tritici-repentis/wheat interaction. Can. J. Plant Pathol. 20:421-424.

3. Ciuffetti, L. M., Tuori, R. P., and Gaventa, J. M. 1997. A single gene encodes a selective toxin causal to the development of tan spot of wheat. Plant Cell 9:135-144.

4. Duveiller, E., van Ginkel, M., and Dubin, J. 1998. Helminthosporium diseases of wheat: Summary of group discussions and recommendations. Pages 1-5 in: Helminthosporium Blights of Wheat: Spot Blotch and Tan Spot. E. Duveiller, H. J. Dubin, J. Reeves, and A. McNab, eds. International Maize and Wheat Improvement Center, Mexico, D.F.

5. Faris, J. D., Anderson, J. A., Francl, L. J., and Jordahl, J. G. 1996. Chromosomal location of a gene conditioning insensitivity in wheat to a necrosis-inducing culture filtrate from Pyrenophora tritici-repentis. Phytopathology 86:459-463. 
6. Haughn, G. W., and Somerville, C. 1986. Sulfonylurea-resistant mutants of Arabidopsis thaliana. Mol. Gen. Genet. 204:430-434.

7. Kwon, C. Y., Rasmussen, J. B., Francl, L. J., and Meinhardt, S. W. 1996. A quantitative bioassay for necrosis toxin from Pyrenophora triticirepentis based on electrolyte leakage. Phytopathology 86:1360-1363.

8. Kwon, C. Y., Rasmussen, J. B., and Meinhardt, S. W. 1998. Activity of Ptr ToxA from Pyrenophora tritici-repentis requires host metabolism. Physiol. Mol. Plant Pathol. 52:201-212.

9. Lamari, L., Ballance, G. M., Orolaza, N. P., and Kowatsch, R. 1995. In planta production and antibody neutralization of the Ptr necrosis toxin from Pyrenophora tritici-repentis. Phytopathology 85:333-338.

10. Lamari, L., and Bernier, C. C. 1989. Evaluation of wheat for reaction to tan spot (Pyrenophora tritici-repentis) based on lesion type. Can. J. Plant Pathol. 11:49-56.

11. Lamari, L., and Bernier, C. C. 1989. Toxin of Pyrenophora triticirepentis: Host-specificity, significance in disease, and inheritance of host reaction. Phytopathology 79:740-744.

12. Lamari, L., and Bernier, C. C. 1991. Genetics of tan necrosis and extensive chlorosis in tan spot of wheat caused by Pyrenophora triticirepentis. Phytopathology 81:1092-1095.

13. Lamari, L., Gilbert, J., and Tekauz, A. 1998. Race differentiation in Pyrenophora tritici-repentis and survey of physiological variation in western Canada. Can. J. Plant Pathol. 20:396-400.
14. Lamari, L., Sayoud, R., Boulif, M., and Bernier, C. C. 1995. Identification of a new race in Pyrenophora tritici-repentis: Implications for the current pathotype classification system. Can. J. Plant Pathol. 17:312318.

15. Panaccione, D. G., Scott-Craig, J. S., Pocard, J. A., and Walton, J. D. 1992. A cyclic peptide synthetase gene required for pathogenicity of the fungus Cochliobolus carbonum on maize. Proc. Natl. Acad. Sci. USA 89: 6590-6594.

16. Riede, C. R., Francl, L. J., Anderson, J. A., Jordahl, J. G., and Meinhardt, S. W. 1996. Additional sources of resistance to tan spot of wheat. Crop Sci. 36:771-777.

17. Scheffer, R. P. 1983. Toxins as chemical determinants of plant disease. Pages 1-40 in: Toxins and Plant Pathogenesis. J. M. Daly and B. J. Deverail, eds. Academic Press, New York.

18. Stock, W. S., Brûlé-Babel, A. L., and Penner, G. A. 1996. A gene for resistance to a necrosis-inducing isolate of Pyrenophora tritici-repentis located on 5BL of Triticum aestivum cv. Chinese Spring. Genome 39:598-604.

19. Tuori, R. P., Wolpert, T. J., and Ciuffetti, L. M. 1995. Purification and immunological characterization of toxic components from cultures of Pyrenophora tritici-repentis. Mol. Plant-Microbe Interact. 8:41-48.

20. Zhang, H.-F., Francl, L. J., Jordahl, J. G., and Meinhardt, S. W. 1997. Structural and physical properties of a necrosis-inducing toxin from Pyrenophora tritici-repentis. Phytopathology 87:154-160. 